\title{
IMPLEMENTASI PUBLIC RELATION PADA KLINIK TERAPI RUQYAH SYAR'IYYAH DPW QHI LAMPUNG SEBAGAI RESPON ATAS MENINGKATNYA TREND HALAL LIFESTYLE
}

\author{
Anissa*, Arif Sugiono, Fenny Saptiani \\ Jurusan Ilmu Administrasi Bisnis, Fakultas Ilmu Sosial dan Politik, Universitas Lampung \\ *anissasyakiraa@gmail.com
}

\begin{abstract}
This study aims to determine the implementation of public relations in the therapy clinic ruqyah syar' iyyah DPW QHI Lampung. This study used a descriptive method with a qualitative approach. The results show that the implementation of public relations in the treatment clinic of ruqyah syar'iyyah DPW QHI Lampung, consisted of publications, events or events, community service activities, and media identity. It is necessary to increase creativity and innovation in public relation programs, as well as the development of informants to study more comprehensively the relationship ruqyah with trend of halal lifestyle.
\end{abstract}

Keywords: therapy ruqyah syar'iyyah, public relation, halal lifestyle

\begin{abstract}
ABSTRAK
Penelitian bertujuan untuk mengetahui implementasi public relation pada klinik terapi ruqyah syar'iyyah DPW QHI Lampung. Penelitian ini menggunakan metode deskriptif dengan pendekatan kualitatif. Hasil penelitian menunjukkan bahwa implementasi public relation pada klinik terapi ruqyah syar'iyyah DPW QHI Lampung terdiri dari publikasi, peristiwa atau acara, kegiatan pelayanan masyarakat, dan media identitas. Perlu adanya peningkatan kreativitas dan inovasi pada program public relation, serta pengembangan informan untuk mengkaji lebih komprehensif keterkaitan ruqyah dengan trend halal lifestyle.
\end{abstract}

Kata kunci: ruqyah, public relation, halal lifestyle

\section{PENDAHULUAN}

Berdasarkan data state of global islamic economy report (2018), upaya menerapkan halal lifestyle tidak hanya kalangan negara muslim saja, tetapi negara-negara yang berpenduduk mayoritas nonmuslim juga tengah berupaya untuk menerapkan halal lifestyle dalam kehidupan sehari-hari. Halal lifestyle memiliki tujuh sektor yang memberikan kontribusi 
besar dalam perekonomian dunia, yaitu halal travel, halal food, Islamic finance, modest fashion, halal media E recreation, halal cosmetics $\mathcal{E}$ halal pharmaceuticals.

Konsep halal mengacu dari aturan yang terdapat dalam Al-Qur'an. Ahmad Rafiq (2012) menguraikan bahwa persepsi Al-Qur'an mengambil bentuk praktik kultural di masa lalu dan saat ini. Pengkajian dalam $A l-Q u r^{\prime} a n$ tidak hanya berupa teks tertulis, tetapi juga mengkaji masyarakat dimana Al-Qur'an dibaca, ditafsirkan, dan dipraktikkan, serta digunakan untuk berbagai tujuan, mulai dari yang bersifat religius hingga keduniaan. Salah satu tujuan penggunaan ayat $A l-Q u r^{\prime}$ an adalah sebagai media pengobatan ruqyah.

Ruqyah syar'iyyah merupakan bentuk pengobatan melalui metode pembacaan ayatayat Al-Quran, dan dihembuskan kepada pasien sesuai dengan tuntunan Rasulullah. Ruqyah Syar'iyyah memiliki tiga syarat, menggunakan ayat-ayat Al-Quran $\mathcal{E}$ hadits tanpa mengubah susunannya, lantunan bahasa Arab yang fasih, tegas dan jelas, dan yakin bahwa Al-Quran dan hadits menjadi sarana untuk mencapai kesembuhan serta yakin bahwa Allah yang akan menyembuhkan. Kemunculan pengobatan ruqyah syar'iyyah diinisiasi oleh berbagai iklim politik dan wacana keislaman di Indonesia, di antaranya jatuhnya rezim orde baru yang memberikan spirit baru bagi wacana keislaman di Indonesia, ketidakpastian jaminan sosial dari pemerintah, dan wacana Islamisme.

Sejak jatuhnya rezim Orde Baru pada tahun 1998, Indonesia menyaksikan tumbuh kembangnya demokrasi, yang ditandai dengan keterbukaan pers dan kemerdekaan berekspresi dalam kerangka demokrasi Pancasila yang menggairahkan. Ihwal ini berkontribusi pada kemunculan aktor-aktor muslim baru yang mulai memproduksi symbol-simbol identitas islam di ruang publik Indonesia. Salvatore \& Eickelman (2004) menyebutnya dengan istilah Islam publik (public Islam). Selain itu, mereka menjelma simbol-simbol Islam dalam variabel-variabel penting di kehidupan muslim perkotaan, seperti produk kosmetik, makanan, pengajian, layanan sosial-ekonomi, khotbah public, dan kebijakan negara. Ruqyah adalah salah satu bentuk layanan kesehatan yang mewarisi semangat kebangkitan Islam pasca era orde baru.

Para praktisi ruqyah mulai menyebarkan gagasan pengobatan ruqyah dengan mendirikan klinik ruqyah, menggelar pelatihan, dan praktik ruqyah di masjid-masjid umum, kampus dan lainnya. Salah satunya yakni klinik terapi ruqyah syar'iyyah DPW QHI (Dewan Perwakilan Wilayah Qur'anic Healing Internasional) Lampung, sebagai klinik layanan kesehatan dengan menggunakan teknik pengobatan alternatif Al-Qur'an dan As-sunnah. Secara berkala, QHI mengadakan pelatihan dan pembinaan teknik pengobatan halal kepada masyarakat umum yang ingin belajar mendalami ilmu ruqyah, bekam dan thibun nabawi melalui event ruqyah massal, dan open recruitment sebagai implikasi dari pelaksanaan public relation.

Sebagai institusi penyedia jasa layanan kesehatan pengobatan alternatif, public relation menjadi bagian penting dalam memasarkan jasa yang ditawarkan. Kegiatan pemasaran harus mencakup distribusi sejumlah ide maupun jasa melalui kerjasama organisasi (public relation) yang dapat memenuhi kebutuhan dan kepuasan kepada konsumen, sehingga segala usaha yang dilakukan dapat terus berjalan dengan baik. Hal ini disebut sebagai integrated marketing communication.

Integrated marketing communication sangat berperan penting bagi perusahaan atau organisasi, terutama pada aspek public relation. Kotler \& Armstrong (2012:454) mengatakan bahwa public relation melibatkan program yang didesain untuk menginformasikan dan melindungi citra dan produk atau layanan organisasi. Lebih lanjut Kotler \& Keller 
(2016:229) menjelaskan perusahaan tidak hanya harus berhubungan secara konstruktif dengan pelanggan, pemasok dan distributor, tetapi juga harus saling berhubungan dengan sebagian besar masyarakat yang berminat dengan produk atau jasa yang dihasilkan. Menurut Aswad Ishak (2012) suatu organisasi baik kecil, sedang ataupun besar pada dasarnya akan selalu membutuhkan sentuhan komunikasi aktif untuk menumbuhkan partisipasi masyarakat dalam pengembangan operasional organisasi.

Public relation memiliki fungsi promosi yang menggunakan komunikasi dua arah untuk menyesuaikan kebutuhan dan minat organisasi, instansi atau lembaga dengan kebutuhan dan minat masyarakat. Alat komunikasi ini dapat menarik perhatian stakeholder jika memiliki kredibilitas yang tinggi, dan tidak memasukkan unsur penjualan, sehingga hanya berfungsi sebagai media distribusi informasi internal kepada eksternal organisasi. Peran public relation dinilai semakin penting karena pengaruhnya dalam organisasi.

Pada umumnya public relation merupakan alat komunikasi yang berhubungan dengan gaya interaksi pendekatan dengan masyarakat luas, yang diperlukan untuk mempengaruhi organisasi lain dan individu. Beberapa alat komunikasi pemasaran yang digunakan sebagai media dalam public relation diantaranya: publikasi, peristiwa/acara, kegiatan kemasyarakatan, dan media identitas.

Pengelolaan kegiatan komunikasi menjadi suatu keharusan yang dilakukan oleh communication specialist. Karena pelaksanaan komunikasi yang baik, akan berdampak pada persepsi positif terhadap produk atau jasa pada klinik terapi ruqyah syar'iyyah DPW QHI Lampung. Dengan demikian, penelitian ini berupaya untuk mengkaji bagaimana implementasi public relationpada klinik terapi ruqyah syar'iyyah DPW QHI Lampung sebagai respon atas meningkatnya trend halal lifestyle.

\section{METODE PENELITIAN}

Penelitian ini menggunakan metode deskriptif pendekatan kualitatif. Lokasi penelitian dilakukan di DPW QHI Lampung. Informan penelitian ditentukan dengan teknik purposive sampling dengan 5 informan. Data primer dan sekunder dalam penelitian ini diperoleh melalui hasil indepth interview, participan observation, dan studi pustaka sekaligus sebagai data triangulasi. Analisis data menggunakan model interaktif Milles dan Huberman (2018), diantaranya pengumpulan data, reduksi data, penyajian data dan penarikan kesimpulan/verifikasi.

\section{PEMBAHASAN}

Berdasarkan analisis data di lapangan, peneliti memperoleh hasil bahwa implikasi public relation pada klinik terapi ruqyah syar'iyyah DPW QHI Lampung terdiri dari publikasi, peristiwa atau acara, kegiatan pelayanan masyarakat dan media identitas.

1. Publikasi

Adapun publikasi yang dilakukan oleh DPW QHI Lampung adalah berupa pamflet dan materi audio visual yang diinformasikan kepada pasien dan calon pasien melalui grup konsultasi ruqyah syar'iyyah, yang dibentuk untuk media konsultasi antara pasien dengan 
terapis. Dalam proses publikasi dan penyampaian informasi, DPW QHI juga bekerjasama dengan radio dan televisi swasta dalam memberikan materi dan informasi mengenai pengobatan halal sunnah, dengan maksud agar informasi ini dapat menjangkau semua kalangan dari anak muda hingga orang tua. Dalam hal ini, QHI Lampung menjalin kerjasama dengan A-Radio 101,1 FM, sebagai salah satu saluran radio Lampung. Seperti yang diungkapkan oleh terapis ruqyah DPW QHI Lampung :

"QHI Lampung sudah bekerjasama dengan salah satu saluran radio dan

tidak berbayar. Siaran dilakukan setiap kamis malam tentang ruqyah

syar'iyyah lalu diakhir dengan sesi tanya jawab bersama pendengar".

Data diatas sesuai dengan apa yang dikemukakan oleh Liliweri (2011), bahwa publikasi adalah informasi yang mempunyai nilai berita, dan sengaja dirancang untuk memperlihatkan, memperkenalkan, mempertahankan nama dan kehormatan seseorang, kelompok atau suatu organisasi kepada khalayak umum dalam suatu konteks tertentu, melalui media, dengan tujuan untuk menciptakan daya tarik khalayak.

Publikasi merupakan pesan yang dengan sengaja direncanakan, dieksekusi, dan didistribusikan melalui media tertentu untuk memenuhi kepentingan publik tanpa harus membayar biaya kepada media. Fungsi publikasi adalah menciptakan citra positif dimata publik, citra positif dapat terbentuk bila publik memiliki persepsi positif terhadap organisasi. Proses publikasi dapat membantu memudahkan DPW QHI Lampung agar lebih dikenal oleh masyarakat. Tujuan dari publikasi ini dimaksudkan agar masyarakat Lampung khususnya tidak lagi asing dengan pengobatan halal terapi ruqyah syar'iyyah.

\section{Peristiwa/Acara}

Ruqyah massal adalah salah satu peristiwa atau acara yang sengaja diciptakan oleh DPW QHI Lampung untuk menarik perhatian masyarakat terhadap praktik pengobatan halal sunnah ruqyah syar'iyyah. Acara dalam kegiatan public relation DPW QHI Lampung dilakukan melalui kerjasama dengan berbagai pihak, diantaranya UKM Birohmah Universitas Lampung, UKM Bapinda Universitas Islam Negeri Raden Intan Lampung, UKM Al-Ittihad, UKM As-Salam Darmajaya, DKM Masjid Al-Hikmah, DKM Masjid AlWasi' i, Sister \& Brother Fillah, Muslimah Care, dan beberapa yayasan pendidikan di Bandar Lampung.

Berbagai acara yang diadakan oleh DPW QHI Lampung telah menarik perhatian organisasi, instansi, dan media, diantaranya organisasi FSLDK (Forum Study Lembaga Dakwah Kampus), MUI (Majelis Ulama Indonesia) Lampung, Trans 7 sebagai saluran televisi swasta nasional, dan Info Kyai sebagai salah satu akun media informasi di Lampung. Data tersebut peneliti peroleh melalui hasil wawancara dengan Ustadz Ariza Abdulrahim selaku Ketua DPW QHI Lampung:

“DPW QHI Lampung memiliki program yang memang sengaja dibuat.

Secara berkala, DPW QHI Lampung mengadakan ruqyah massal yang bekerjasama dengan organisasi di Bandar Lampung, dan programnya memang gratis".

Pernyataan sejenis dikemukakan oleh Kennedy (2009) dalam arti sempit, peristiwa atau acara adalah suatu pertunjukan, dengan syarat ada penyelenggara dan peserta. Sedangkan dalam arti luas, peristiwa adalah kegiatan yang dilakukan setiap hari, bulan atau tahun oleh sebuah organisasi dengan mendatangkan orang-orang kesuatu tempat, agar mereka mendapatkan suatu informasi atau pengalaman penting, serta tujuan lain yang diselenggarakan oleh penyelenggara. Peristiwa merupakan acara yang sengaja diciptakan 
untuk memperoleh perhatian dan penerimaan publik.

Peristiwa atau acara yang layak diberitakan, dapat menciptakan publisitas, dan menarik liputan media. Peristiwa berupa acara publisitas yang sukses, mengandung nilai berita, menampilkan foto, video, rekaman suara, dan mengomunikasikan pesan secara nyata, dan mengundang media untuk menjadikannya sumber berita.

Peristiwa atau acara merupakan sarana public relation yang cukup sering digunakan dalam rangka memperkenalkan produk perusahaan pada masyarakat secara luas. Peristiwa atau acara menjadi salah satu sarana komunikasi yang dianggap lebih dipercaya daripada iklan. Hal ini dikarenakan peristiwa atau acara tampak lebih nyata dalam eksekusinya. Acara ruqyah massal gratis adalah salah satu program dari public relation DPW QHI Lampung yang berkerjasama dengan departemen kaderisasi dan instansi di Bandar Lampung, dengan maksud agar terjalin koordinasi yang baik dalam menyebarluaskan informasi melalui media, mengenai pengobatan halal sunnah ruqyah syar'iyyah dan mempermudah proses perekrutan anggota baru.

\section{Kegiatan Pelayanan Masyarakat}

Di dalam pelaksanaan program public relation, DPW QHI Lampung memiliki program kerja khusus bagi masyarakat secara gratis dalam bentuk aktivitas kunjungan terjadwal ke masjid-masjid yang ada di Bandar Lampung. Dilansir dalam website MUI (Majelis Ulama Indonesia) Provinsi Lampung, bahwa sejak Februari 2017 QHI Lampung telah meluncurkan program silaturrahmi pekanan kepada masyarakat Kota Bandar Lampung. Pernyataan tersebut diungkapkan oleh terapis ruqyah syar'iyyah DPW QHI Lampung:

“DPW QHI Lampung menawarkan kepada masyarakat Bandar Lampung, khususnya, bagi siapa saja yang ingin mengadakan kegiatan seputar ruqyah syar'iyyah secara gratis dengan menghubungi ke nomor 085832825268". (http://mui-lampung.or.id diakses pada 23 Januari 2019)

Pernyataan tersebut sejalan dengan Uchjana(2011), bahwa fungsi kegiatan pelayanan masyarakat pada organisasi atau perusahaan adalah sebagai berikut:

a. Menunjang kegiatan manajemen organisasi dalam mencapai tujuan.

b. Membina hubungan harmonis antara organisasi dengan publik

c. Menciptakan komunikasi dua arah, dengan menyebarkan informasi dari organisasi kepada publik, dan menyalurkan opini publik kepada organisasi.

d. Melayani publik dan memberi nasehat kepada pimpinan organisasi demi kepentingan bersama.

e. Membina hubungan harmonis antara organisasi dengan publik untuk mencegah terjadinya hambatan psikologis yang mungkin saja timbul.

Public relation merupakan bagian dari organisasi yang berfungsi untuk menjaga hubungan baik antara organisasi dengan konsumen, serta masyarakat umum. Suatu organisasi atau perusahaan dapat meningkatkan citra positif di masyarakat dengan memberikan waktu dan pelayanan khusus dengan baik. Tugas public relation DPW QHI Lampung dalam kegiatan pelayanan masyarakat adalah melakukan sinkronisasi antara informasi dari internal organisasi dengan reaksi dan tanggapan publik, sehingga tercapai perasaan akrab dan saling mengerti untuk menimbulkan suasana yang menyenangkan dalam interaksi organisasi dengan masyarakat. 


\section{Media Identitas}

Media identitas yangditunjukkan oleh DPW QHI Lampung adalah logo, kartu nama, brosur dan seragam. Media identitas tersebut digunakan untuk memperkuat brand dari organisasi tersebut. Seperti pernyataan yang diungkapkan oleh salah satu praktisi ruqyah:

"Media identitas kita salah satunya logo, seragam dan kartu nama. Terapis yang membuka praktik dirumah juga wajib pasang atribut QHI, seperti banner juga harus menyantumkan logo QHI, jadi legalitasnya tidak lagi dipertanyakan pasien. Selain itu, kita juga memiliki produk herbal yang memang diproduksi langsung oleh QHI pusat".

Kotler \& Keller (2016) mengatakan bahwa organisasi atau perusahaan membutuhkan identitas visual yang langsung dikenal masyarakat. Identitas visual tersebut terdapat dalam logo perusahaan, alat tulis, brosur, tanda, formulir bisnis, kartu nama, bangunan, seragam, dan aturan berpakaian. Penggunaan media identitas adalah salah satu langkah untuk memperkenalkan produk atau jasa yang ditawarkan kepada konsumen agar dapat mudah dikenali melalui apa yang tampak ketika proses pelayanan berlangsung.

Bahan identitas perusahaan juga bisa membantu menciptakan identitas perusahaan yang segera disadari masyarakat. Bahan ini meliputi lambang, alat tulis, brosur, tanda, berkas bisnis, kartu bisnis, gedung seragam, serta kendaraan perusahaan. Semuanya mampu menjadi sarana pemasaran dalam public relation jika sarana tersebut atraktif, berbeda, dan mudah diingat. Media identitas menjadi sesuatu yang sangat penting dalam sebuah perusahaan, selain sebagai sarana memperkenalkan, media identitas juga merupakan jati diri bagi organisasi atau perusahaan yang membedakannya dengan organisasi lain.

Klinik terapi ruqyah syar'iyyah DPW QHI Lampung memiliki logo khusus pada banner, kemasan produk herbal, dan tanda pengenal. Selain itu, DPW QHI Lampung juga mewajibkan terapisnya menggunakan seragam saat menangani pasien. Identitas tersebut digunakan untuk membedakan DPW QHI Lampung dengan organisasi lain, sekaligus menjadi jati diri dalam mempertahankan eksistensinya.

\section{PENUTUP}

Dalam penelitian ini, peneliti memperoleh hasil bahwa implementasi public relation pada klinik terapi ruqyah syar'iyyah DPW QHI Lampung terdiri dari publikasi, peristiwa atau acara, kegiatan pelayanan masyarakat, dan media identitas, dimana aktivitas tersebut adalah program yang didesain sebagai media distribusi informasi untuk mencapai tujuan organisasi.

Perlu adanya peningkatan kreativitas dan inovasi pada program public relation, seperti pemberian sponsor, pembuatan house jurnal, atau mengadakan event festival, dan mengadakan program social investment berkala yang dapat membantu proses public relation agar DPW QHI Lampung semakin dikenali oleh masyarakat luas.

Keterbatasan penelitian ini pada informan, menjadi pengembangan penting dalam penelitian selanjutnya dalam menggali informasi, khususnya persepsi atau pandangan konsumen melihat terapi ruqyah sebagai trend halal lifestyle dalam teknik pengobatan, sehingga menyajikan hasil penelitian yang lebih komprehensif. 


\section{DAFTAR PUSTAKA}

Adisaputro, G. (2010). Manajemen pemasaran: Analisis untuk perancangan strategi pemasaran. Yogyakarta: Sekolah Tinggi Ilmu Manajemen YKPN.

Alo, L. (2011). Komunikasi antar personal. Jakarta: Remaja Rosdakarya.

Argenti, P. A. (2010). Komunikasi korporat. Jakarta: Salemba Humanika.

Belch, G. E., \& Michael, B. A. B. (2018). Advertising and promotion: An integrated marketing communication perspective. New York: Mc Graw-Hill Companies, Inc.

Diwati, F., \& Santoso, T. I. (2015). “Pengaruh strategi integrated marketing communication (IMC) terhadap keputusan membeli konsumen pada bisnis tour \& travel di wilayah Daerah Istimewa Yogyakarta. Jurnal EBANK, 6(2).

Duncan, T. (2002). IMC-using advertising and promotion to build brand. New York: Mc Graw-Hill.

Fealy, G. (2008). Consuming Islam: Commodified religion and aspirational pietism in contemporary Indonesia." Greg Fealy \& Sally White, (eds.). Expressing Islam: Religious life and politics in Indonesia. Singapore: Institute of Southeast Asian Studies.

Hasan, Ali. (2010). Marketing dari mulut ke mulut, Cetakan 1. Yogyakarta: Media Pressindo.

Hendika, D., \& Arifin, Z., \& Sunarti. (2015). “Analisis strategi pemasaran untuk meningkatkan daya saing UMKM (Studi pada batik Diajeng Solo). Jurnal Administrasi Bisnis, 29(1).

Ishak, A. (2012). "Peran public relation dalam komunikasi organisasi”. Jurnal Komunikasi, 1(4).

Ismail, M., \& Murnisari, R. (2017). “Analisis efektivitas strategi integrated marketing communication guna meningkatkan kepuasan konsumen CV. Barisan Nyawiji Meubel Malang". Jurnal Penelitian Manajemen Terapan (Penatran), 2(1).

Kotler, P. (2000). Marketing management, analysis, planning, implementation and control, Internasional Edition. New Jersey: Prentice Hall, Inc.

Kotler, P., \& Armstrong. G. (2012). Principle of marketing, 14th Edition. New Jersey: Prentice Hall, Inc.

Kotler, P., \& Armstrong, G. (2012). Principle of marketing. 13th Edition. New Jersey: Prentice Hall, Inc.

Kotler, P., \& Keller, K. L. (2016). Marketing management, 15th Edition. England: Pearson Education, Inc.

Lovelock, C., \& Gummesson. (2011). Pemasaran jasa, 7th Ed. (Alih Bahasa Dian Wulandari \& Devri Barnadi Putera). Jakarta: Erlangga.

Makmur, S. (2015). “Strategi pemasaran dalam meningkatkan volume penjualan (Studi pada S-Mart swalayan Pasir Pengaraian). Jurnal Ilmiah Cano Ekonomos, 3(1).

Miles, M. B., Huberman, A. M., \& Saldana. (2014). Qualitative data analysis, a methods sourcebook, 3th Ed. (Alih Bahasa Tjetjep Rohindi Rohidi). Jakarta: UI-Press.

Olga, S. (2014). "Strategi media relation Ciputra World Surabaya dalam special event halloweenation 2013". Jurnal E-Komunikasi, 2(1).

Purnomo, A. P. (2010). "Pengaruh publisitas pada image selebritis di mata penggemar (Studi pada grup band Keris Patih)". Skripsi. Depok: Universitas Indonesia. Diakses dari [http:/ / lib.ui.ac.id/ file?file=digital/131930SK\%200012010\%20Pur\%20p $\% 20$ \%20Pengaruh\%20publisitas\%20-\%20Literatur.pdf].

Raharja, S. J. (2016). “Formulation of strategic planning base on environment: Studies in five organizations. Jurnal AdBispreneur, 1(3).

Rangkuti, F. (2009). Strategi promosi yang kreatif \& analisis kasus integrated marketing communication. Jakarta: PT. Gramedia Pustaka Utama.

Robbins, S. P., \& Judge, T. A. (2008). Perilaku organisasi. Jakarta: Salemba Empat.

Robbins, S. P., \& Matthew, M. (2009). Organization theory: Structure, design, and applications, 3rd Ed. England: Pearson Education.

Rosady, R. (2010). Manajemen public relation dan media komunikasi. Jakarta: Rajawali Pers.

Salvatore, A., \& Dale F. E. (2004). Public Islam and the common good. Leiden \& Boston: Brill.

Shimp, T. A. (2003). Periklanan promosi aspek tambahan komunikasi pemasaran terpadu. Jakarta: Erlangga.

Sugiyono. (2017). Metode penelitian bisnis: Pendekatan kuantitatif, kualitatif, dan R \& D. Bandung: Alfabeta.

Sugiyono. (2013). Metodologi penelitian kuantitatif, kualitatif, dan R \& D. Bandung: Alfabeta.

State Of Global Economy Report 2018/2019. (2020). Diakses dari [https://halalfocus.net/state-of-the-globalislamic-economy-report-2018-19/1 
Tjiptono, F. (2017). Strategi pemasaran, Edisi 3. Yogyakarta: Andi.

Tjiptono, F. (2014). Pemasaran jasa: Prinsip, penerapan dan penelitian. Yogyakarta: Andi.

Wayuningsih, L. (2013). “Tugas dan fungsi public relation dalam organisasi”. Tugas Akhir. Yogyakarta: D3 Adminsitrasi Perkantoran, Fakultas Ekonomi, Universitas Negeri Yogyakarta. Diakses dari [http://eprints.uny.ac.id/17895/1/TUGAS\%20AKHIR.pdf] 